\title{
Role of Soybean mosaic virus-Encoded Proteins in Seed and Aphid Transmission in Soybean
}

\author{
Sushma Jossey, Houston A. Hobbs, and Leslie L. Domier
}

First and second authors: Department of Crop Sciences, and third author: United States Department of Agriculture-Agricultural Research Service, Department of Crop Sciences, University of Illinois, Urbana 61801. Accepted for publication 2 March 2013.

\begin{abstract}
Jossey, S., Hobbs, H. A., and Domier, L. L. 2013. Role of Soybean mosaic virus-encoded proteins in seed and aphid transmission in soybean. Phytopathology 103:941-948.

Soybean mosaic virus (SMV) is seed and aphid transmitted and can cause significant reductions in yield and seed quality in soybean (Glycine max). The roles in seed and aphid transmission of selected SMV-encoded proteins were investigated by constructing mutants in and chimeric recombinants between SMV 413 (efficiently aphid and seed transmitted) and an isolate of SMV G2 (not aphid or seed transmitted). As previously reported, the DAG amino acid sequence motif near the amino terminus of the coat protein $(\mathrm{CP})$ was the major determinant in differences in aphid

transmissibility of the two SMV isolates, and helper component proteinase (HC-Pro) played a secondary role. Seed transmission of SMV was influenced by P1, HC-Pro, and CP. Replacement of the P1 coding region of SMV 413 with that of SMV G2 significantly enhanced seed transmissibility of SMV 413. Substitution in SMV 413 of the two amino acids that varied in the CPs of the two isolates with those from SMV G2, G to $\mathrm{D}$ in the DAG motif and Q to P near the carboxyl terminus, significantly reduced seed transmission. The Q-to-P substitution in SMV 413 also abolished virus-induced seed-coat mottling in plant introduction 68671. This is the first report associating P1, CP, and the DAG motif with seed transmission of a potyvirus and suggests that HC-Pro interactions with $\mathrm{CP}$ are important for multiple functions in the virus infection cycle.
\end{abstract}

Soybean mosaic virus (SMV) is transmitted by aphids and through seed and infects soybean (Glycine $\max (\mathrm{L}$.) Merr.), where it can cause yield reductions as high as $35 \%$ (29). SMV has been reported worldwide from all soybean-growing areas (29) and is a member of the genus Potyvirus (family Potyviridae), one of the largest genera of plant viruses (24). SMV-infected seed serve as the primary source of inoculum in the field because there are very few alternative hosts of the virus in North America (29). Seed transmission of 0 to $43 \%$ has been reported, with specific SMV strain-soybean-line interaction required for seed transmission $(7,19)$. In Pea seed-borne mosaic virus (PSbMV) (genus Potyvirus), helper component proteinase (HC-Pro) and virus genomic RNA containing the regions encoding nuclear inclusion body a (NIa) and b (NIb) proteins were associated with seed transmission (32). In PSbMV, infection of the embryo and suspensor cells occurred before maturation from the endosperm through transient vesicles at the base of the suspensor at the micropylar region (48). PSbMV invaded the endosperm through plasmodesmata from the testa. The presence of the virus in the micropylar region before the degeneration of the transient vesicles in the suspensor was necessary for embryo invasion (48). In SMV, survival of the virus within the maturing embryo also plays an important role in seed transmission (6).

In soybean, susceptibility to seed transmission of SMV has been linked to the chromosomal regions that contain genes predicted to encode homologues of Dicer-like 3 and RNA-dependent

Corresponding author: L. L. Domier;

E-mail address: leslie.domier@ars.usda.gov

* The $\boldsymbol{e}$-Xtra logo stands for "electronic extra" and indicates that the online version contains one supplemental table.

http://dx.doi.org/10.1094/PHYTO-09-12-0248-R

This article is in the public domain and not copyrightable. It may be freely reprinted with customary crediting of the source. The American Phytopathological Society, 2013.
RNA polymerase 6 that are involved in antiviral defense through RNA silencing (17). P1 and HC-Pro of potyviruses have been implicated in suppression of gene silencing $(20,34,41,61)$. HCPro also has been associated with virus movement and aphid transmission $(5,12,49)$. NIa, a serine protease, is one of the three endopeptidases encoded by potyviruses that process their polyproteins $(9,27)$. NIb is the RNA-dependent RNA polymerase required for virus replication (18).

SMV is spread in the field primarily by noncolonizing aphids in a nonpersistent manner (29). Although SMV is transmitted efficiently by the soybean-colonizing aphid Aphis glycines Matsumura in laboratory experiments $(10,30)$, the importance of $A$. glycines as a vector for transmission of SMV in the field is unclear $(8,44)$. Aphid transmission of most potyviruses has been proposed to be dependent on the interaction between HC-Pro and the coat protein (CP) $(5,16,22,54)$. The KLSC amino acid sequence motif near the $\mathrm{N}$ terminus of SMV HC-Pro has been implicated in binding to $A$. glycines stylets (54) and a second amino acid sequence motif, PTK, in the HC-Pro of Zucchini yellow mosaic virus (ZYMV) has been implicated in binding to virus CP (45). However, the PTK motif of SMV failed to influence HC-Pro interactions with CP, although it was important in aphid transmission (54). The DAG amino acid sequence motif of the CP is conserved in most potyviruses and facilitates transient binding to HC-Pro during aphid transmission $(2,5,39)$. The DAG motif of SMV has also been linked to aphid transmission by A. glycines (54). Several other conserved amino acid residues in HC-Pro and CP of specific potyviruses have been linked to aphid transmission $(16,22,38,54)$.

Pigmentation of soybean seed coats is governed by alleles at the $I$ locus that regulate chalcone synthase (CHS) mRNA levels by post-transcriptional gene silencing $(53,58,59)$. Chalcone synthase is an important enzyme in the flavonoid pathway that synthesizes anthocyanin and proanthocyanidin pigments. In some soybean genotypes, the I locus contains multiple copies of CHS genes organized into perfect inverted repeats (11). Small interfering RNAs produced from these inverted repeats silence CHS 
gene expression that results in yellow- instead of black-pigmented seed $(11,59)$. In soybean infected with SMV, seed with SMVinduced seed-coat mottling had higher CHS mRNA levels in the seed coat than the uninfected seed, which was attributed to the suppression of gene silencing by SMV HC-Pro (53).

In a previous study, it was observed that SMV isolates that were efficiently transmitted through seed were also efficiently transmitted by aphids (19). To study the role of SMV proteins P1, HC-Pro, Nib, and CP, and amino acid residues within CP in aphid and seed transmission, chimeric and mutant viruses were produced from two SMV isolates with high and low seed and aphid transmission rates. The effects of the virus proteins and amino acid residues on foliar symptoms and seed-coat mottling were also investigated.

\section{MATERIALS AND METHODS}

Virus isolates and plant materials. The full-length infectious clones of field isolate SMV 413 (17), SMV strain G2 (60) (provided by J. Hill, Iowa State University, Ames as a cDNA clone of isolate SMV N), and recombinants between the two unmodified viruses were used to investigate seed and aphid transmission in this study. SMV 413 and SMV G2 were seed transmitted in soybean plant introduction (PI) 68671 at rates of 32 and $0 \%$, respectively, and were transmitted by aphids at rates of 67 and $0 \%$, respectively, in 'Williams 82' soybean (19).

Virus inoculum for SMV 413 was prepared from systemically infected leaves of Williams 82 that had been mechanically inoculated at the unifoliate stage with capped in vitro transcripts (17). The SMV G2 clone $(14.5 \mathrm{~kb})$ was biolistically inoculated using the Helios Gene Gun system (Bio-Rad, Hercules, CA) as recommended by the manufacturer, with $1.6-\mu \mathrm{m}$ gold particles at a rate of $0.125 \mathrm{mg}$ of gold particles per shot and $1 \mu \mathrm{g}$ of plasmid DNA per shot (61). The recombinants were inoculated mechanically as in vitro transcripts or biolistically depending on whether the promoter for the recombinant viruses was derived from the SMV 413 or SMV G2 clone.

Seed of 'PI 68671' were obtained from the United States Department of Agriculture Soybean Germplasm Collection, Urbana, IL. Aphid transmission studies were conducted using virusfree soybean Williams 82, obtained from Missouri Foundation Seed, University of Missouri, Columbia. Soybean plants were grown in 2:1 soil/soilless (Metro-Mix 900; Sun-Gro Horticulture Inc., Bellevue, WA) mix at 25 to $27^{\circ} \mathrm{C}$ with a 12 -h photoperiod.

Sequence analysis. Infectious clones of SMV 413 and SMV G2 (GenBank accession numbers GU015011 and D00507, respectively) were sequenced using primers spaced $1 \mathrm{~kb}$ apart (Supplemental Table 1) as described earlier. Primers were designed using Primer3 (51). Sequencher 4.7 (Gene Codes, Ann Arbor, MI) and DNAMAN (Lynnon BioSoft, Quebec, QC, Canada) were used for sequence assembly, amino acid sequence predictions, and sequence alignments. The nucleotide sequence of the cloned SMV N isolate of SMV G2 differed from the sequence previously deposited for SMV-N at positions 4,495 $(\mathrm{C} \rightarrow \mathrm{A}), 4,960(\mathrm{~A} \rightarrow \mathrm{G})$, $5,129(\mathrm{G} \rightarrow \mathrm{A})$, 5,463 $(\mathrm{G} \rightarrow \mathrm{A})$, 6,488 $(\mathrm{A} \rightarrow \mathrm{G})$, 6,650 $(\mathrm{G} \rightarrow \mathrm{A})$, 7,031 $(\mathrm{C} \rightarrow \mathrm{G})$, 7,297 $(\mathrm{A} \rightarrow \mathrm{T})$, 7,376 $(\mathrm{G} \rightarrow \mathrm{A})$, and 8,987 $(\mathrm{A} \rightarrow \mathrm{G})$.

Construction of chimeric SMV clones. Chimeric mutants pG4-Sal and p4G-Sal were constructed using the unique SalI restriction enzyme sites present at nucleotide position 3,786 in SMV 413 and nucleotide 3,782 in SMV G2 (Fig. 1A) and NotI sites present in the plasmid vectors at nucleotide positions 13,109 and 13,597 in SMV 413 and SMV G2 clones, respectively. The NotI-SalI fragment from the 5' terminus of SMV G2 was ligated (T4 DNA ligase; Promega Corp., Madison, WI) with the NotI-SalI fragment from the $3^{\prime}$ terminal region of SMV 413 and vice versa to make pG4-Sal and p4G-Sal, respectively (Fig. 1B).

The role of HC-Pro in seed and aphid transmission was examined by reciprocally exchanging the coding sequences for HC-
Pro between SMV G2 and SMV 413 to produce chimeric SMV clones pG2-HPmut and p413-HPmut, respectively (Fig. 1B). These clones were developed using a unique $S a c$ II restriction site present near the $5^{\prime}$ terminus of the HC-Pro coding region in SMV 413 and BlpI sites present near the $3^{\prime}$ terminus of the HC-Pro coding region in both full-length cDNA clones (Fig. 1A).

The chimeric clone pG2-HPmut was developed by first designing pG2- $\triangle \mathrm{HP}$, an SMV G2 clone lacking the HC-Pro coding sequence, by inverse polymerase chain reaction (PCR) with iProof High-Fidelity DNA polymerase (Bio-Rad) using primers G2Hc-BlpI3050F (with MluI and BlpI sites) and G2Hc-SacII1857R (with MluI and SacII sites) (Supplemental Table 1). The PCR product was digested with MluI and cloned. The pG2-HPmut clone was constructed by inserting the $S a c \mathrm{II} / B l p \mathrm{I}$-digested SMV 413 fragment containing the HC-Pro coding region into SacIIBlpI-digested pG2- $\triangle \mathrm{HP}$.

The chimeric clone $\mathrm{p} 413-\mathrm{HPmut}$ was constructed by inserting a SacII site at the $5^{\prime}$ terminus of the HC-Pro coding sequence of SMV G2 by PCR, using primer G2-HcPro-SacIIF and G2-HcProBlpIR with iProof DNA polymerase. The p413-HPmut was developed by inserting SacII/BlpI-digested PCR-amplified SMV G2 HC-Pro into the SacII-BlpI fragment of SMV 413 lacking the HC-Pro coding region.

The influence of NIb protein on seed and aphid transmission was studied with p413-NIbmut, which was constructed by introducing BglII and PpuMI sites near the $5^{\prime}$ and the $3^{\prime}$ termini of the NIb coding region of SMV G2 (Fig. 1A) with primers G2-6954$B g l \mathrm{IIF}$ and G2-8556-PpuMIR. The chimeric clone p413-NIbmut was developed by inserting $B g / \mathrm{II} / \mathrm{PpuMI}$-digested PCR-amplified SMV G2 NIb also containing the DAD motif from the $\mathrm{N}$ terminus of the CP into the $B g l \mathrm{II}-P p u \mathrm{MI}$ fragment of SMV 413 lacking the $\mathrm{NIb}$ coding region (Fig. 1B).

To determine the significance of $\mathrm{P} 1$ protein in seed and aphid transmission, p413-P1mut was constructed by exploiting the SacII site present in SMV 413 (Fig. 1A) similar to p413-HPmut and $\mathrm{p} 413-\mathrm{NIbmut}$. The p413-P1mut was engineered by inserting NotI/SacII-digested $\mathrm{pG} 2-\Delta \mathrm{HP}$ containing the $\mathrm{P} 1$ coding region of SMV G2 into the NotI-SacII fragment of SMV 413 lacking the P1 coding sequence (Fig. 1B).

The amino acid sequences of the CPs of SMV 413 and SMV G2 differed at positions 12 in the DAG motif and 264. The conserved DAG amino acid motif in the $\mathrm{CP}$ of most potyviruses is implicated in aphid transmission and interaction with the HC-Pro $(5,54)$. SMV G2, which was not aphid or seed transmitted, has a DAD rather than DAG motif in the $\mathrm{CP}$ (Fig. 2A). The role of this motif and its interaction with HC-Pro in aphid and seed transmission was investigated using two sets of site-specific point mutant clones. First, the DAG motif was changed to DAD in SMV 413 and p413-HPmut to produce p413-CPmut and p413-DM, respectively, by substituting nucleotides GC at positions 35 and 36 of the CP coding region of SMV 413 with AT by site-directed mutagenesis. The clones were developed (Fig. 1B) by overlapextension PCR (28) using iProof DNA polymerase with primers 413-CP1-BglIIF and 413-CP1-mut1R (413-CP1-mut2F and 413CP1-MluIR). Mutants p413-CP1mut and p413-DM were developed by inserting the BglII- and MluI-digested PCR products containing the G12 to D mutation in the CP into BglII-MluI fragments of SMV 413 and p413-HPmut lacking the 3' end, respectively.

A second set of point-mutant clones was constructed where the DAD amino acid sequence motifs in SMV G2, p4G-Sal, and pG2HPmut were mutated to DAG by overlap-extension PCR to produce pG2-CPmut, p4G-Sal-CP, and pG2-DM, respectively (Fig. 1). The clones were developed using iProof DNA polymerase with primers G2-CP1-AgeIF, G2-CP1-mut1R, G2-CP1-mut2F, and G2-CP1-NheIR. The pG2-CPmut, p4G-Sal-CP, and pG2-DM were developed by inserting AgeI/NheI-digested PCR products containing the D12 to G mutation in the CP into AgeI-NheI 
fragments of SMV G2, p4G-Sal, and pG2-HPmut lacking the 3' end, respectively.

In addition to the $G$ to $D$ mutation in their DAG motifs, the $C P$ amino acid sequences of SMV 413 and SMV G2 also differed by a single amino acid substitution of $\mathrm{Q}$ to $\mathrm{P}$ at position 264. To investigate the role of this amino acid substitution in seed and aphid transmission, $\mathrm{Q}$ was mutated to $\mathrm{P}$ with a single nucleotide change of $\mathrm{A}$ to $\mathrm{C}$ at nucleotide position 791 in the CP of SMV 413 and p413-CP1 (Fig. 2B) to develop p413-CP2mut and p413CP-DM, respectively (Fig. 1B). The substitution was carried out by overlap-extension PCR with primers 413-CP1-BglIIF, 413CP2-mut1R, 413-CP2-mut2F, and 413-CP1-MluIR. The point- mutation clones p413-CP2mut and p413-CP-DM were engineered by inserting $B g l \mathrm{II} / \mathrm{MluI}$-digested PCR products containing the Q264 to P mutation in the CP into BglII-MluI fragments of SMV 413 and p413-CP1 lacking the $3^{\prime}$ end, respectively. The construction of all mutant clones was verified by sequencing.

Seed transmission. The influence of SMV-encoded proteins on seed transmission rates was investigated with SMV 413, SMV G2, and the 13 SMV chimera and mutants in PI 68671 soybean. Seed of PI 68671 were germinated and seedlings were tested for SMV infection by tissue-blot immunoassay (TBIA) prior to seed transmission studies using alkaline phosphatase enzyme conjugate for SMV (Agdia, Inc., Elkhart, IN) (36). SMV-free PI 68671

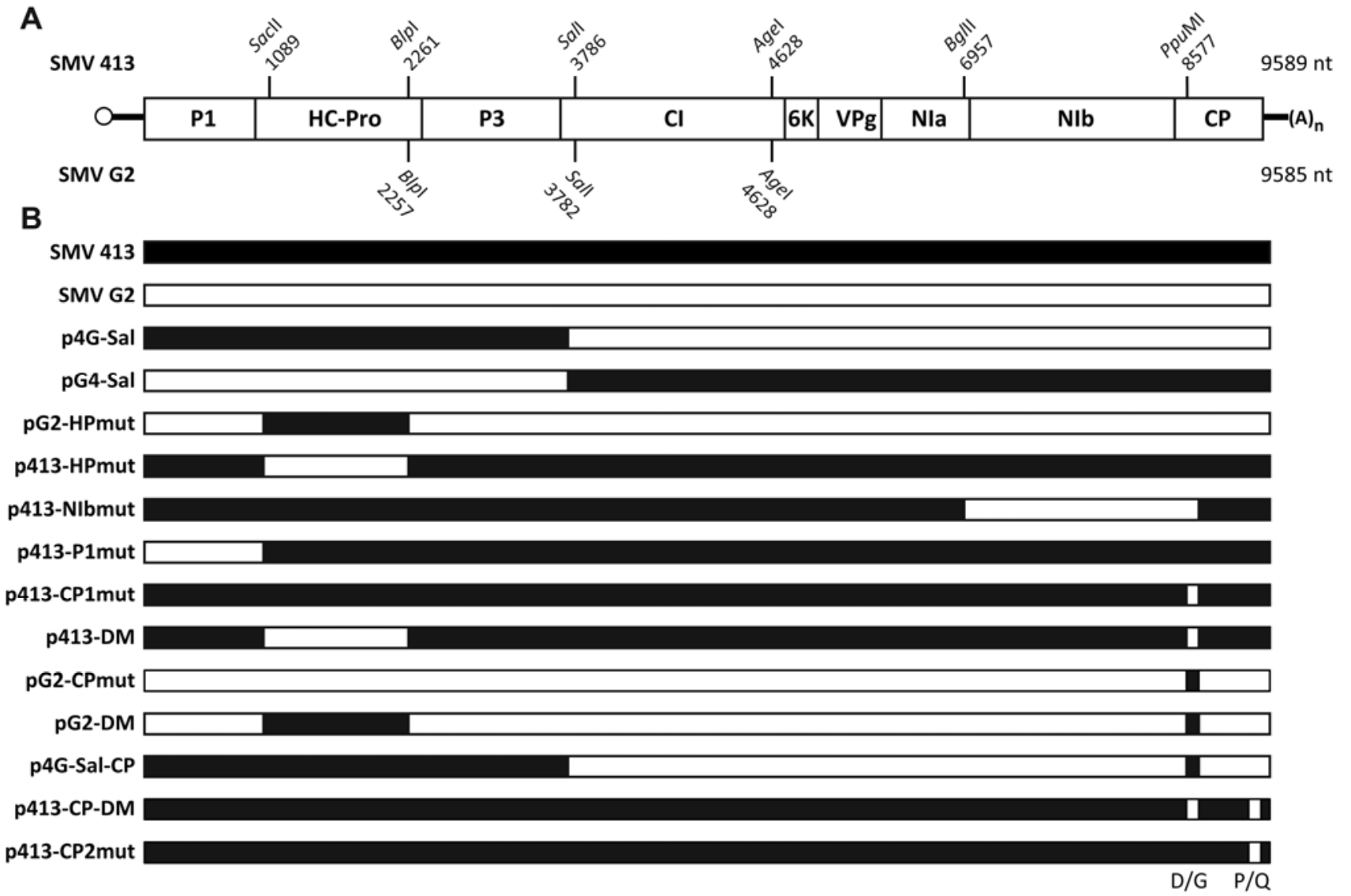

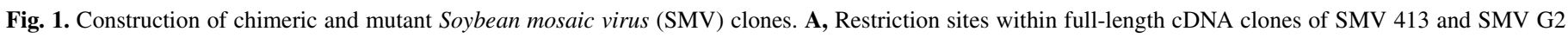

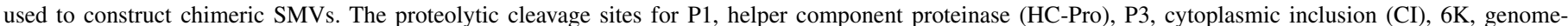

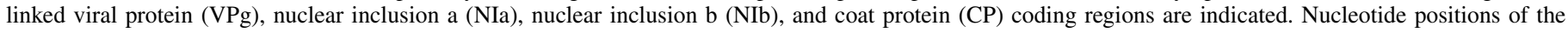

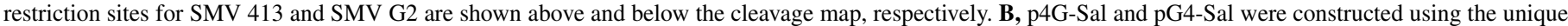

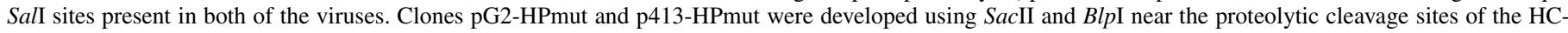

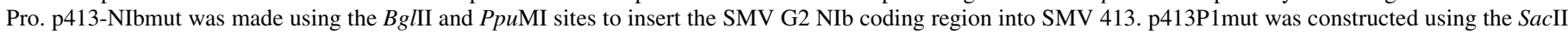

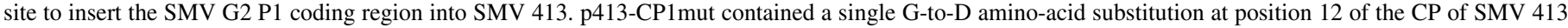

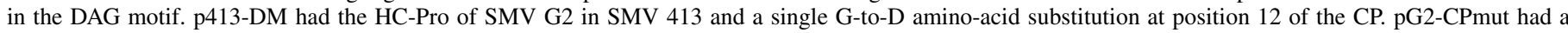

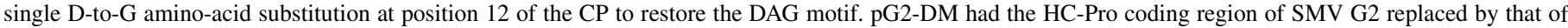

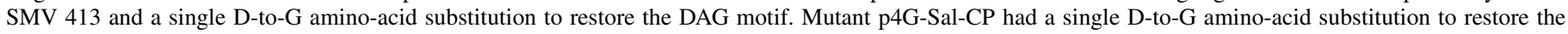

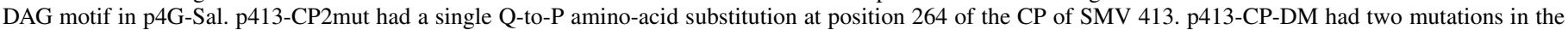
CP of SMV 413, the G-to-D at position 12 and the Q-to-P at position 264.

A 1

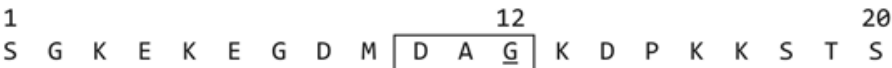
SMV 413 TCAGGCAAGGAGAAAGAAGGAGACATG GATGCAGGC AAGGACCCAAAGAAGAGTACCAGC |||||||||||||| |||||||| ||| ||||||| ||||| ||||||||||| ||||| SMV G2 TCAGGCAAGGAGAAGGAAGGAGATATG GATGCAGAT AAGGATCCAAAGAAGAGCACCAGT \begin{tabular}{lllllllll|lll|llllllll}
$S$ & $G$ & $K$ & $E$ & $K$ & $E$ & $G$ & $D$ & $M$ & $D$ & $A$ & $\underline{D}$ & $K$ & $D$ & $P$ & $K$ & $K$ & $S$ & $T$ & $S$
\end{tabular}
B 253 SMV 413 CAAAACATGCACACTCTTCTGGGCATGGGCCCACAGGAGTAA |||||||||||||||||||||||||||||||||||| $\mid$ SMV G2 CAAAACATGCACACTCTTTTGGGCATGGGCCCACC GCAGTAA

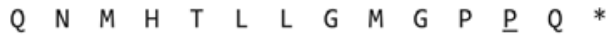

Fig. 2. Mismatches in the nucleotide and predicted amino acid sequences near the amino and carboxyl termini in the coat proteins (CPs) of Soybean mosaic virus (SMV) 413 and SMV G2. A, In the first 60 nucleotides of the CP coding regions, nucleotide sequence differences at position 35 and 36 (underlined) produce an amino acid change of G in SMV 413 to D in SMV G2 in the DAG motif (boxed) that is associated with aphid transmission of potyviruses. The other nucleotide changes are translationally silent. B, The single nucleotide mismatch at position 791 (underlined) results in a single amino acid change of Q at position 264 in SMV 413 to P in SMV G2 (underlined). 
seedlings were mechanically inoculated at the V2 growth stage (21) using extracts prepared from Williams 82 individually infected with each unmodified isolate and mutant SMV clone. Extracts were prepared in $10 \mathrm{mM}$ sodium phosphate buffer $(\mathrm{pH}$ 7.0) and rubbed on Carborundum (Fisher)-dusted leaves with pestles. Infections were confirmed by sequencing reverse-transcription (RT)-PCR products from symptomatic leaves from inoculated plants. Total RNA was extracted from $100 \mathrm{mg}$ of plant tissue using RNeasy Plant Mini Kit (Qiagen Inc. Valencia, CA). First-strand cDNA was synthesized using Superscript II reverse transcriptase (Invitrogen Corp., Carlsbad, CA) using appropriate primers. The first-strand cDNA was amplified for sequencing using primers specific to the site of recombination of the SMV chimeras.

For each replication, mature seed were harvested from plants infected with each of the unmodified and chimeric or mutant SMV clones, and seed transmission rates were determined using grow-out tests by planting 108 seeds (or as few as 49 seeds for extremely severe chimera that produced few seeds) in 72-well polystyrene trays (1.5 trays per mutant or chimera per replication) containing soilless mix (Sunshine Mix LC1; Sun Gro Horticulture Inc., Bellevue, WA). SMV infection of seedlings was determined by visual inspection. The experiment was conducted in three replications in the greenhouse at 25 to $27^{\circ} \mathrm{C}$ with a 12 -h photoperiod. Average germination percentages and seed transmission rates of the modified or unmodified SMVs were compared using a generalized linear model assuming a binomial distribution with a logit link function in PROC GLIMMIX in SAS. A constant value, 0.375 , was added to each data point to eliminate zero values, which inflated the standard error of means.

Symptom severity. The severity of symptoms produced by each unmodified or mutant virus was recorded 30 days after inoculation using a scale of 1 to 3 , where $1=$ mosaic on foliage; $2=$ mosaic and rugosity; and $3=$ mosaic, rugosity with reduction in leaf lamina and leaf curling, and severe stunting in soybean PI 68671 that were used for seed transmission studies. The relative accumulation of virus RNAs in leaf tissues were quantified in plants infected with mutant viruses and compared with the average accumulation in SMV 413 and SMV G2 using quantitative real-time (q)RT-PCR (Power SYBR Green RNA-to-CT 1-Step Kit; Applied Biosystems Inc., Foster City, CA) with soybean actin as the internal control (37). Total RNA was extracted as described above from $100 \mathrm{mg}$ of leaf tissue pooled from five

TABLE 1. Symptom severity in 'PI 68671' at 30 days after inoculation and mottling of mature seed coats from 'PI 68671' plants infected by unmodified Soybean mosaic virus (SMV) 413, SMV G2, or mutants derived from the two isolates

\begin{tabular}{lcc}
\hline SMV clones & Symptom severity $^{\mathrm{a}}$ & Seed coat mottling $^{\mathrm{b}}$ \\
\hline SMV 413 & 2 & Mottled \\
SMV G2 & 2 & Unmottled \\
p4G-Sal & 1 & Unmottled \\
pG4-Sal & 3 & Mottled \\
pG2-HPmut & 1 & Unmottled \\
p413-HPmut & 3 & Mottled \\
p413-NIbmut & 2 & Mottled \\
p413-P1mut & 2 & Mottled \\
p413-CP1mut & 2 & Mottled \\
p413-DM & 3 & Mottled \\
pG2-CPmut & 2 & Unmottled \\
pG2-DM & 1 & Unmottled \\
p4G-Sal-CP & 1 & Unmottled \\
p413-CP2mut & 2 & Unmottled \\
p413-CP-DM & 2 & Unmottled
\end{tabular}

a Symptom severity score: 1 = mosaic on foliage; 2 = mosaic and rugosity; $3=$ mosaic, rugosity with reduction in leaf lamina and leaf curling and severe stunting.

b Seed coat mottling: Unmottled = yellow seed; Mottled = seed with brown pigmentation. plants, and qRT-PCR was carried out with SMV real-time universal primers SMV4618F and SMV4742R and specific primers for soybean actin gene SAc1-317F and SAc1-463R. The thermal cycling conditions for qRT-PCR were $48^{\circ} \mathrm{C}$ for $30 \mathrm{~min}$ for RT and $95^{\circ} \mathrm{C}$ for $10 \mathrm{~min}$ for activation of the polymerase, followed by 40 cycles of $95^{\circ} \mathrm{C}$ for $15 \mathrm{~s}$ and $60^{\circ} \mathrm{C}$ for $1 \mathrm{~min}$. The experiment was conducted with three biological replications and two or three technical repetitions for each treatment. SMV RNA accumulation levels were statistically compared as described above.

Aphid transmission. The aphid transmissibilities of the recombinant and point-mutation viruses were conducted on Williams 82 with apterous aphids (A. glycines) that were maintained in controlled environment chambers at $24^{\circ} \mathrm{C}$ on SMV-free Williams 82 plants. Aphids were collected and starved for $30 \mathrm{~min}$ and given an acquisition access period (AAP) of 2 min on infected leaves from each SMV clone. Accumulation of SMV RNA in the infected leaf tissue of Williams 82 used in the AAP was quantified using qRTPCR as described earlier. Ten unifoliate seedlings were inoculated with each of the 15 unmodified or mutant SMVs by transferring five aphids to each plant for an inoculation access period (IAP) of $24 \mathrm{~h}$. Aphid-infested plants during the IAP were placed in cages to avoid aphid movement among plants. The plants were fumigated for $2 \mathrm{~h}$ with Hot Shot No-Pest Strips (Chemsico, St. Louis) in a controlled-environment chamber and then maintained in the greenhouse for 3 weeks for symptom expression at 25 to $27^{\circ} \mathrm{C}$ with a 12-h photoperiod. Plants were assayed for SMV by TBIA or by sequencing of RT-PCR products as described earlier. Aphid transmission rates were statistically compared as described above.

\section{RESULTS}

Symptom severity. SMV 413 and SMV G2 shared $96.93 \%$ identity in their predicted amino acid sequences and produced similar symptoms on the vegetative tissues of PI 68671 that included stunting and foliar symptoms of mosaic, rugosity, and leaf curling; however, some mutant viruses induced different levels of symptom severity (Table 1). Clones p4G-Sal, p4G-Sal-CP, pG2$\mathrm{DM}$, and pG2-HPmut produced symptoms that were less severe than SMV 413 and SMV G2. Clones p413-CP1mut, p413-CP2mut, p413-CP-DM, p413-NIbmut, p413-P1mut, and pG2-CPmut produced symptoms with severities similar to those induced by SMV 413 and SMV G2. However, clones pG4-Sal, p413-HPmut, and p413-DM produced symptoms much more severe than those produced by SMV 413 and SMV G2. Replacing the HC-Pro coding region in SMV 413 with that of SMV G2 was associated with increased symptom severity and replacing the HC-Pro coding region of SMV G2 with that of SMV 413 was associated with decreased symptom severity. Because the accumulation of SMV RNAs did not differ significantly $(P>0.05)$ among the mutants in PI 68671 at 30 days postinoculation (data not shown), the variability of the symptoms induced by the clones was not the result of differential levels of SMV RNA accumulation in infected tissues.

Seed-coat mottling. Seed from PI 68671 infected with unmodified SMV 413 or SMV G2 or the mutant viruses were differentially mottled. Seed from plants infected with SMV 413 showed seed-coat mottling but, when infected with SMV G2, seed were not mottled (Table 1). Seed coats from plants infected with clones p413-CP1mut, p413-NIbmut, p413-P1mut, p413HPmut, p413-DM, and pG4-Sal showed extensive pigmentation. Clones p413-CP2mut, p413-CP-DM, pG2-CPmut, pG2-HPmut, pG2-DM, p4G-Sal, and p4G-Sal-CP did not induce seed-coat mottling. Because all of the clones that did not induce mottling contained at least the $3^{\prime}$ terminal region of the SMV G2 coding region, and SMV 413 and $\mathrm{p} 413 \mathrm{CP} 2$ mut differed only at the Q-to$\mathrm{P}$ at position 264 in the $\mathrm{CP}$, the results indicate that the loss of SMV-induced seed-coat mottling in soybean PI 68671 was linked to a single amino acid residue change near the $\mathrm{C}$ terminus of the CP (Fig. 2B). 
Seed transmission. Seed transmission rates of SMV mutants in PI 68671 were influenced by multiple protein coding regions and specific amino acid residues in the SMV genome ( $F$ test was significant at $P<0.0001)$. Because the accumulation of SMV RNAs did not differ significantly among the mutants in PI 68671, differences in levels of seed transmission were not correlated with accumulation of virus RNA. Unmodified SMV G2 was not transmitted through seed and SMV 413 was seed transmitted in $14 \%$ of the seedlings. Only unmodified SMV 413 and the chimeric clone p413-P1mut were transmitted through seed. The P1 coding region of SMV G2 increased seed transmission rates in SMV 413. p413-P1, a chimeric SMV 413 containing the P1 coding region from SMV G2, had the highest seed transmission rate of $26 \%$, which was significantly higher $(P=0.002)$ than SMV 413 (Fig. 3 ). None of the other mutants or chimera were transmitted through seed at rates that differed significantly $(P>0.05)$ from the nonseed-transmitted SMV G2 (Fig. 3). The chimeric clone pG4-Sal had very low seed set due to extremely severe virus symptoms and was not included in the grow-out tests to determine seed transmission.

The lack of seed transmission of $\mathrm{p} 4 \mathrm{G}-\mathrm{Sal}$ and $\mathrm{p} 4 \mathrm{G}-\mathrm{Sal}-\mathrm{CP}$ indicated that regions in addition to $\mathrm{P} 1$, HC-Pro, and $\mathrm{CP}$, possibly including CI, NIa, Nib, or $\mathrm{VpG}$, may influence seed transmission. The predicted amino acid sequences of the $6 \mathrm{~K}$ proteins were identical between the unmodified SMV isolates. The substitution of the HC-Pro coding region of SMV 413 in p413-HPmut and p413-DM with that of SMV G2 resulted in the loss of seed transmission, implicating HC-Pro in seed transmission. Mutations to SMV 413 amino acid residue G12 in the amino acid motif DAG of the $\mathrm{CP}$ in $\mathrm{p} 413-\mathrm{CP} 1$ mut and the $\mathrm{Q}$ amino acid residue at position 264 near the $\mathrm{C}$ terminus (Fig. 2) of CP in p413-CP2mut led to the loss of seed transmission, implicating both amino acids in seed transmission. Replacement of HC-Pro in SMV G2 in pG2HPmut or the restoration of the DAG amino acid motif (Fig. 1B) at the $\mathrm{N}$ terminus in the $\mathrm{CP}$ in $\mathrm{pG} 2-\mathrm{CPmut}$ or both the mutations together in pG2-DM did not affect seed transmission rates, which remained at $0 \%$, similar to SMV G2. Mutant 413-NIbmut, in which a cDNA fragment including all of the NIb coding sequence, and the amino terminus of the $\mathrm{CP}$ including the DAD motif from SMV G2 substituted into SMV 413 (Fig. 2A), had very low seed transmission that was not significantly different from SMV G2; however, because of the presence of the DAD rather than DAG motif in the mutant, it was not possible to evaluate the effects of NIb on seed transmission alone.

Aphid transmission. Transmission of SMV by A. glycines in Williams 82 soybean was dependent on the SMV isolate $(F$ value significant at $P<0.0001$ ), with the point-mutant p413-CP2mut transmitted at the highest rate of 63\% (Fig. 4). Aphid transmission rates of SMV 413, pG2-DM, p4G-Sal-CP, and p413-P1mut did not differ significantly $(P>0.05)$ from the highest transmission rate recorded in p413-CP2mut. SMV G2, pG4-Sal, pG2-HPmut, p4G-Sal, p413-NIbmut, p413-DM, p413-CP-DM, and p413CP1mut were not aphid transmitted, and pG2-CPmut was transmitted by aphids to very few plants at a rate not significantly different from non-aphid-transmitted, unmodified SMV G2 $(P=$ 0.50). The mutant p413-HPmut had a low aphid transmission, which was not significantly different from pG2-DM $(P=0.05$, aphid transmitted) or SMV G2 $(P=0.21$, not aphid transmitted $)$ (Fig. 4).

The aphid transmissibility of SMV G2 was restored in pG2DM by the introduction of HC-Pro from SMV 413 and the DAG motif in the CP (Figs. 1B and 2). Loss of the DAG motif from the unmodified SMV 413 in p413-CP1mut abrogated aphid transmission. The mutant $\mathrm{p} 4 \mathrm{G}-\mathrm{Sal}-\mathrm{CP}$, with the $5^{\prime} 3.8 \mathrm{~kb}$ of the virus derived from SMV 413 and the 3' $5.8 \mathrm{~kb}$ of the virus derived from SMV G2 and the DAD motif converted to DAG, was efficiently aphid transmitted whereas p4G-Sal was not aphid transmitted. These results illustrate the importance of the DAG motif of the $\mathrm{CP}$ in aphid transmission. The substitution of $\mathrm{Q}$ to $\mathrm{P}$ at amino acid position 264 near the $C$ terminus of the CP of SMV 413 in p413CP2mut did not affect aphid transmission (Fig. 2B). SMV protein $\mathrm{P} 1$, which is the most variable protein between the unmodified SMVs (88.6\% amino acid sequence identity), did not influence the transmission rates, as evident from efficient aphid transmission of p413-P1mut. The HC-Pro coding region played a secondary role in aphid transmission, which was evident by the observation that p413-HPmut, an SMV 413 clone containing the HCPro coding sequence from SMV G2, had an aphid transmission rate that did not differ significantly from SMV 413 but the SMV 413 clone containing just a mutation in the DAG motif (p413-

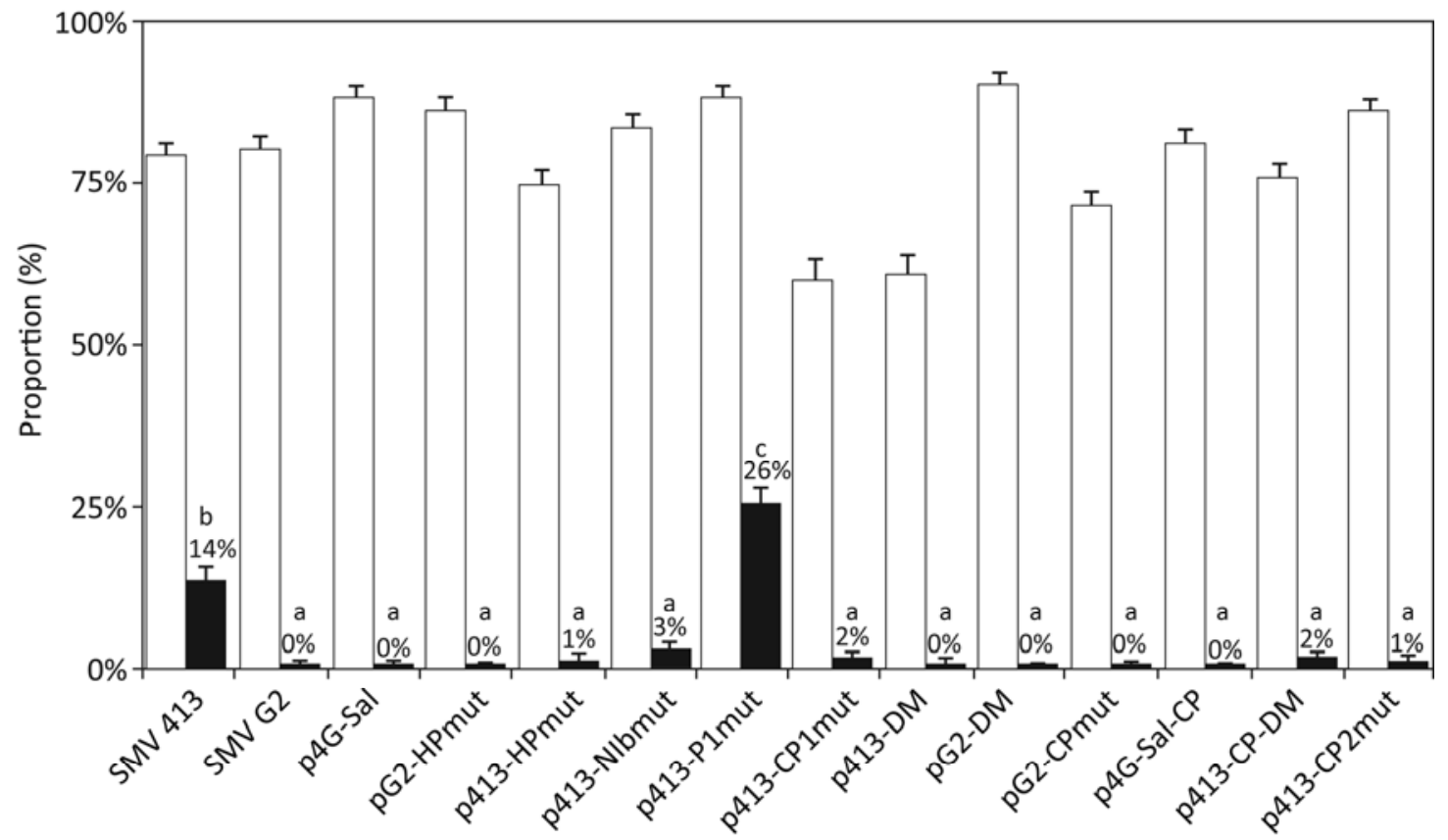

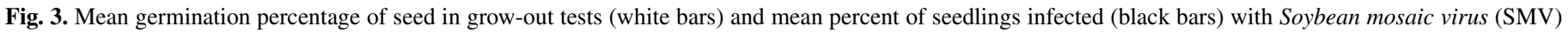

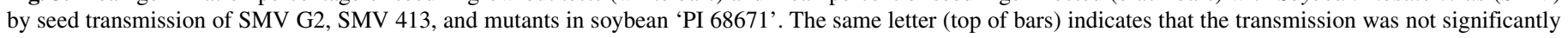
different (based on confidence interval at $\alpha=0.05$ ). Error bars indicate the standard errors of means. 
CP1mut) had an aphid transmission rate significantly less than SMV 413. However, full restoration of aphid transmission in SMV G2 required the replacement of HC-Pro with SMV 413 HCPro and insertion of the DAG motif.

\section{DISCUSSION}

In this study, we investigated the association of regions of the SMV genome in seed and aphid transmission using SMV 413 and SMV G2 and chimera or mutants engineered from the two viruses and showed that $\mathrm{HC}$-Pro and $\mathrm{CP}$ sequences are required for aphid transmission and transmission of SMV through seed. Even though SMV 413 and SMV G2 produced similar symptoms in soybean accession PI 68671, the chimeric viruses differed in foliar symptom severity and the levels of seed-coat mottling they induced. Similar to results reported by Paalme et al. (42) for recombinants constructed from two closely related strains of Potato virus A, some recombinant SMVs produced symptoms more or less severe than the parental viruses. The HC-Pro coding region was associated with these changes in SMV symptom severity in PI 68671. HC-Pro has been reported to be involved in symptom development in Plum pox virus $(26,52)$ and ZYMV $(13,35)$. In ZYMV, the amino acid motif CDNQLD was responsible for symptom severity (13). However, the motif was conserved in SMV 413 and SMV G2. HC-Pro is a suppressor of gene silencing $(20,40,41)$. Suppressors of gene silencing can affect symptom severity (35) but P1, also linked to suppression of gene silencing (25), had no effect on the symptom severity of the virus isolates tested in PI 68671.

Previous studies found that the extent of seed-coat mottling and seed transmission are dependent on host genotype, the isolate of SMV used, the interactions between soybean cultivar and SMV isolate $(19,31,46,57)$, and the soybean growth stage at the time of infection (47). Induction of seed-coat mottling by SMV has been linked to suppression of RNA silencing by the viruses and the

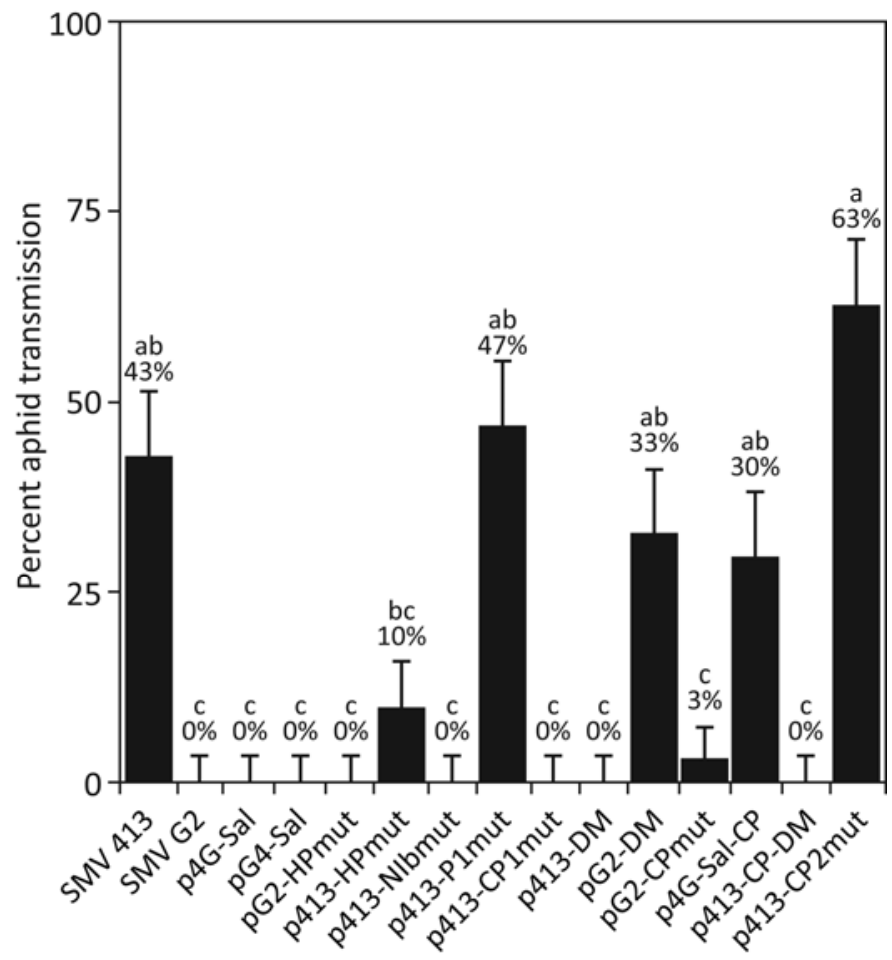

Fig. 4. Percent aphid transmission by Aphis glycines of Soybean mosaic virus (SMV) isolates SMV G2, SMV 413, and chimeric or mutant clones in soybean 'Williams 82 ' with the mean of percent aphid transmission; the same letter (top of the bars) indicates that the transmission was not significantly different (based on confidence interval at $\alpha=0.05$ ). Error bars indicate the standard errors of means. suppression of tissue-specific silencing of CHS gene expression (54). Somewhat surprisingly, the difference in levels of seed-coat mottling induced by SMV 413 and SMV G2 in PI 68671 was linked to a single amino acid change ( $Q$ to $P$ at position 264) near the $\mathrm{C}$ terminus of $\mathrm{CP}$. It should be noted that SMV G2 produces seed-coat mottling in other soybean genotypes and other SMV G2 isolates produce seed-coat mottling in PI 68671 (19), which underscores the specificity of the interactions between virus and host proteins in modulating RNA silencing responses. As has been previously reported, the presence of seed-coat mottling is not a good indicator of seed transmission $(19,43)$, and both seedtransmitted and non-seed-transmitted SMV isolates exhibited seed-coat mottling in PI 68671. For the SMV isolates analyzed here, aphid transmission was influenced primarily by the DAG amino acid sequence motif in the $\mathrm{CP}$, and HC-Pro played a secondary role, which confirms the importance of the DAG motif and HC-Pro in aphid transmission that has been reported in SMV and other potyviruses $(2,4,5,54)$ The role of the DAG motif of CP and HC-Pro was also evident by the restoration of aphid transmission in the nontransmitted SMV G2 with the mutation of D12 to $\mathrm{G}$ in the DAG motif and by replacing the SMV G2 HC-Pro with SMV 413 HC-Pro. The amino acid sequences of HC-Pros of SMV 413 and SMV G2 are $95.6 \%$ identical but the first 100 amino acid residues that are exclusively involved in aphid transmission (15) contained most of the mismatches, with $88 \%$ identity (Fig. 5). Amino acid residues previously associated with aphid transmission were conserved between SMV 413 and SMV G2 $(22,54)$.

Replacement of the region of the SMV 413 genome that encodes the P1 RNA silencing suppressor with that of the non-seedtransmitted SMV G2 produced a chimeric virus with a higher seed transmission rate than the unmodified SMV 413. This result is consistent with the association of chromosomal regions in the soybean genome with genes involved in induction of antiviral RNA silencing with seed transmission of SMV (17). An RNA surveillance system involving RDR6 and DCL 3 excludes pathogens from meristems $(14,23)$ and may also be involved in excluding viruses from the developing seed. HC-Pro, an RNA silencing suppressor, affected seed transmission, as shown by the inhibition of seed transmission in SMV 413 mutants that had HCPro coding region from SMV G2. Johansen et al. (32) also observed the importance of the HC-Pro coding region of PSbMV in seed transmission. These results point to the role of RNA silencing in SMV seed transmission in soybean.

Single-amino-acid changes in the CP of SMV 413 of G12 to D in the DAG motif and Q264 to $\mathrm{P}$ near the $\mathrm{C}$ terminus of $\mathrm{CP}$ abolished SMV seed transmission in PI 68671. The DAG motif is required for aphid transmission of multiple potyviruses and facilitates interactions between SMV HC-Pro and CP (54) but it has not been reported earlier from SMV or any potyviruses to be a determinant of seed transmission. The $\mathrm{N}$ and $\mathrm{C}$ termini of potyvirus $\mathrm{CPs}$ are exposed on the surface of the globular protein and

\section{SMV 4131 SQTPEAQFFRGWKKVFDKMPPHVENHECTIDFTNEQCGEL 60 || ||||||||||||||||||||||||||| |||||||||| \\ SMV G2 1 SQNPEAQFFRGWKKVFDKMPPHVENHECTTDFTNEQCGEL 60 \\ SMV 41341 AAAISQSVFPVK KLSC KQCRQHIKNLSWEEYKQFLLAHMG 80 ||||||$+||||||||||||||||+|||||||||||||| \mid$ \\ SMV G2 41 AAAISQSIFPVK KLSC KQCRQHIKHLSWEEYKQFLLAHMG 80 \\ SMV 41381 CHRAEWENIQKVDGMKYVKKVIETSTAENASLQTSMEIVR 120 I| ||$|++|||+|||+|||||||||||||||+||||$ \\ SMV G2 81 CHGPEWETFQEIDGMRYVKRVIETSTAENASLQTSLEIVR 120}

Fig. 5. Predicted amino acid sequence alignment of 120 amino acid residues from the $\mathrm{N}$ terminus of the helper component protease (HC-Pro) of Soybean mosaic virus (SMV) isolates SMV 413 and SMV G2 with the KLSC amino acid conserved motif indicated in the box. 
virus particles, where they could interact with other proteins or with themselves $(3,33,34,55)$. The $\mathrm{N}$-terminal region of Wheat streak mosaic virus coat protein is a host- and strain-specific long-distance transport factor (56). HC-Pro of Lettuce mosaic virus interacts with $\mathrm{CP}$ that is not assembled into virus particles in vivo and in vitro (50). The influence of the DAG motif, which is required for direct physical interactions between $\mathrm{HC}$-Pro and $\mathrm{CP}$ $(5,45,50,54)$, suggests that such interactions might also be required for seed transmission. Andrejeva et al. (1) found that the DAG motif in CP of Potato virus $A$ was required for both aphid transmission and virus accumulation in plants and suggested that the two processes could be mechanistically linked. Rojas (49) found that both CP and HC-Pro of Bean common mosaic necrosis virus moved from cell to cell and increased the size exclusion limits of plasmodesmata. The findings here suggest that interactions between CP and HC-Pro may also be required for seed transmission of SMV and may affect RNA silencing in a hostspecific manner. Further studies will be required to identify specific regions or amino acid sequences within P1, HC-Pro, and NIb that can influence seed transmission.

\section{ACKNOWLEDGMENTS}

This work was supported by the United States Department of Agriculture Cooperative State Research, Education, and Extension and Agricultural Research Services and the North Central Soybean Association. We thank N. McCoppin for assistance with the aphid transmission experiments and C. Hill for providing Aphis glycine used for the aphid transmission experiments. Mention of a trademark, proprietary product, or vendor does not constitute a guarantee or warranty of the product by the United States Department of Agriculture or the University of Illinois and does not imply its approval to the exclusion of other products or vendors that may also be suitable.

\section{LITERATURE CITED}

1. Andrejeva, J., Puurand, U., Merits, A., Rabenstein, F., Jarvekulg, L., and Valkonen, J. P. T. 1999. Potyvirus helper component-proteinase and coat protein $(\mathrm{CP})$ have coordinated functions in virus-host interactions and the same CP motif affects virus transmission and accumulation. J. Gen. Virol. 80:1133-1139.

2. Atreya, C. D., Raccah, B., and Pirone, T. P. 1990. A point mutation in the coat protein abolishes aphid transmissibility of a potyvirus. Virology 178 161-165.

3. Baratova, L. A., Efimov, A. V., Dobrov, E. N., Fedorova, N. V., Hunt, R., Badun, G. A., Ksenofontov, A. L., Torrance, L., and Jarvekulg, L. 2001. In situ spatial organization of Potato virus $A$ coat protein subunits as assessed by tritium bombardment. J. Virol. 75:9696-9702.

4. Blanc, S., Ammar, E. D., Garcia-Lampasona, S., Dolja, V. V., Llave, C., Baker, J., and Pirone, T. P. 1998. Mutation in potyvirus helper component protein: effects on interactions with virons and aphid stylet. J. Gen. Virol. 79:3119-3122.

5. Blanc, S., Lopez-Moya, J. J., Wang, R., Garcia-Lampasona, S., Thornbury, D. W., and Pirone, T. P. 1997. A specific interaction between coat protein and helper component correlates with aphid transmission of a potyvirus. Virology 231:141-147.

6. Bowers, G. R., and Goodman, R. M. 1979. Soybean mosaic virus: Infection of soybean seed parts and seed transmission. Phytopathology 69:569-572.

7. Bowers, G. R., and Goodman, R. M. 1991. Strain specificity of soybean mosaic virus seed transmission in soybean. Crop Sci. 31:1171-1174

8. Burrows, M. E. L., Boerboom, C. M., Gaska, J. M., and Grau, C. R. 2005. The relationship between Aphis glycines and Soybean mosaic virus incidence in different pest management systems. Plant Dis. 89:926-934.

9. Carrington, J. C., Haldeman, R., Dolja, V. V., and Restrepo-Hartwig, M. A. 1993. Internal cleavage and trans-proteolytic activities of the VPg-proteinase (NIa) of Tobacco etch potyvirus in vivo. J. Virol. 67:6995-7000.

10. Clark, A. J., and Perry, K. L. 2002. Transmissibility of field isolates of soybean viruses by Aphis glycines. Plant Dis. 86:1219-1222.

11. Clough, S. J., Tuteja, J. H., Li, M., Marek, L. F., Shoemaker, R. C., and Vodkin, L. O. 2004. Features of a 103-kb gene-rich region in soybean include an inverted perfect repeat cluster of $C H S$ genes comprising the $I$ locus. Genome 47:819-831.

12. Cronin, S., Verchot, J., Haldeman-Cahill, R., Schaad, M. C., and Carrington, J. C. 1995. Long-distance movement factor: A transport func- tion of the potyvirus helper component proteinase. Plant Cell 7:549-559.

13. Desbiez, C., Girard, M., and Lecoq, H. 2010. A novel natural mutation in HC-Pro responsible for mild symptomatology of Zucchini yellow mosaic virus (ZYMV, Potyvirus) in cucurbits. Arch. Virol. 155:397-401.

14. Di Serio, F., Martinez de Alba, A. E., Navarro, B., Gisel, A., and Flores, R. 2010. RNA-dependent RNA polymerase 6 delays accumulation and precludes meristem invasion of a viroid that replicates in the nucleus. J. Virol. 84:2477-2489.

15. Dolja, V. V., Herndon, K. L., Pirone, T. P., and Carrington, J. C. 1993. Spontaneous mutagenesis of a plant potyvirus genome after insertion of a foreign gene. J. Virol. 67:5968-5975.

16. Dombrovsky, A., Huet, H., Chejanovsky, N., and Raccah, B. 2005. Aphid transmission of a potyvirus depends on suitability of the helper component and the $\mathrm{N}$ terminus of the coat protein. Arch. Virol. 150:287-298.

17. Domier, L. L., Hobbs, H. A., McCoppin, N. K., Bowen, C. R., Steinlage, T. A., Chang, S., Wang, Y., and Hartman, G. L. 2011. Multiple loci condition seed transmission of Soybean mosaic virus (SMV) and SMVinduced seed coat mottling in soybean. Phytopathology 101:750-756.

18. Domier, L. L., Shaw, J. G., and Rhoads, R. E. 1987. Potyviral proteins share amino acid sequence homology with picorna-, como-, and caulimoviral proteins. Virology 158:20-27.

19. Domier, L. L., Steinlage, T. A., Hobbs, H. A., Wang, Y., HerreraRodriguez, G., Haudenshield, J. S., McCoppin, N. K., and Hartman, G. L. 2007. Similarities in seed and aphid transmission among Soybean mosaic virus isolates. Plant Dis. 91:546-550.

20. Ebhardt, H. A., Thi, E. P., Wang, M., and Unrau, P. J. 2005. Extensive 3' modification of plant small RNAs is modulated by helper componentproteinase expression. Proc. Natl. Acad. Sci. USA 102:13398-13403.

21. Fehr, W. R., Caviness, C. E., Burmood, D. T., and Pennington, J. S. 1971. Stage of development descriptions for soybeans, Glycine max (L.) Merrill. Crop Sci. 11:929-931.

22. Flasinski, S., and Cassidy, B. G. 1998. Potyvirus aphid transmission requires helper component and homologous coat protein for maximal efficiency. Arch. Virol. 143:2159-2172.

23. Foster, T. M., Lough, T. J., Emerson, S. J., Lee, R. H., Bowman, J. L., Forster, R. L., and Lucas, W. J. 2002. A surveillance system regulates selective entry of RNA into the shoot apex. Plant Cell 14:1497-1508.

24. Gibbs, A., and Ohshima, K. 2010. Potyviruses and the digital revolution. Annu. Rev. Phytopathol. 48:205-223.

25. Giner, A., Lakatos, L., Garcia-Chapa, M., Lopez-Moya, J. J., and Burgyan, J. 2010. Viral protein inhibits RISC activity by Argonaute binding through conserved WG/GW motifs. PLoS Pathog. 6:e1000996.

26. Gonzalez-Jara, P., Atencio, F. A., Martinez-Garcia, B., Barajas, D., Tenllado, F., and Diaz-Ruiz, J. R. 2005. A single amino acid mutation in the Plum pox virus helper component-proteinase gene abolishes both synergistic and RNA silencing suppression activities. Phytopathology 95:894-901.

27. Hellmann, G. M., Shaw, J. G., and Rhoads, R. E. 1988. In vitro analysis of tobacco vein mottling virus NIa cistron: Evidence for a virus-encoded protease. Virology 163:554-562.

28. Higuchi, R. 1990. Recombinant PCR. Pages 177-183 in: PCR Protocols: A Guide to Methods and Applications. M. A. Innis, D. H. Gelfand, J. J. Sninsky, and T. J. White, eds. Academic Press, San Diego, CA.

29. Hill, J. H. 1999. Soybean mosaic virus. Pages 70-71 in: Compendium of Soybean Diseases. G. L. Hartman, J. B. Sinclair, and J. C. Rupe, eds. American Phytopathological Society, St. Paul, MN.

30. Hill, J. H., Alleman, R., Hogg, D. B., and Grau, C. R. 2001. First report of transmission of Soybean mosaic virus and Alfalfa mosaic virus by Aphis glycines in the new world. Plant Dis. 85:561.

31. Hobbs, H. A., Hartman, G. L., Wang, Y., Hill, C. B., Bernard, R. L., Pedersen, W. L., and Domier, L. L. 2003. Occurrence of seed coat mottling in soybean plants inoculated with Bean pod mottle virus and Soybean mosaic virus. Plant Dis. 87:1333-1336.

32. Johansen, I. E., Dougherty, W. G., Keller, K. E., Wang, D., and Hampton, R. O. 1996. Multiple viral determinants affect seed transmission of Pea seedborne mosaic virus in Pisum sativum. J. Gen. Virol. 77:3149-3154.

33. Kang, S. H., Lim, W. S., Hwang, S. H., Park, J. W., Choi, H. S., and Kim, K. H. 2006. Importance of the C-terminal domain of soybean mosaic virus coat protein for subunit interactions. J. Gen. Virol. 87:225-229.

34. Kendall, A., McDonald, M., Bian, W., Bowles, T., Baumgarten, S. C., Shi, J., Stewart, P. L., Bullitt, E., Gore, D., Irving, T. C., Havens, W. M., Ghabrial, S. A., Wall, J. S., and Stubbs, G. 2008. Structure of flexible filamentous plant viruses. J. Virol. 82:9546-9554.

35. Lim, H. S., Ko, T. S., Hobbs, H. A., Lambert, K. N., Yu, J. M., McCoppin, N. K., Korban, S. S., Hartman, G. L., and Domier, L. L. 2007. Soybean mosaic virus helper component-protease alters leaf morphology and reduces seed production in transgenic soybean plants. Phytopathology 97:366-372.

36. Lin, N. S., Hsu, Y. H., and Hsu, H. T. 1990. Immunological detection of plant viruses and a mycoplasmalike organism by direct tissue blotting on nitrocellulose membranes. Phytopathology 80:824-828. 
37. Livak, K. J., and Schmittgen, T. D. 2001. Analysis of relative gene expression data using real-time quantitative PCR and the $2^{-\Delta \Delta C T}$ method. Methods 25:402-408.

38. Llave, C., Martinez, B., Diaz-Ruiz, J. R., and Lopez-Abella, D. 2002. Amino acid substitutions within the Cys-rich domain of the tobacco etch potyvirus HC-Pro result in loss of transmissibility by aphids. Arch. Virol. 147:2365-2375.

39. Lopez-Moya, J. J., Wang, R. Y., and Pirone, T. P. 1999. Context of the coat protein DAG motif affects potyvirus transmissibility by aphids. J. Gen. Virol. 80:3281-3288.

40. Merai, Z., Kerenyi, Z., Kertesz, S., Magna, M., Lakatos, L., and Silhavy, D. 2006. Double-stranded RNA binding may be a general plant RNA viral strategy to suppress RNA silencing. J. Virol. 80:5747-5756.

41. Moissiad, G., Parizotto, E. A., Himber, C., and Voinnet, O. 2007. Transitivity in Arabidopsis can be primed, requires the redundant action of the antiviral Dicer-like 4 and Dicer-like 2, and is compromised by viral-encoded suppressor proteins. RNA 13:1268-1278.

42. Paalme, V., Gammelgard, E., Jarvekulg, L., and Valkonen, J. P. T. 2004. In vitro recombinants of two nearly identical potyviral isolates express novel virulence and symptom phenotypes in plants. J. Gen. Virol. 85:739-747.

43. Pacumbaba, R. P. 1995. Seed transmission of Soybean mosaic virus in mottled and nonmottled soybean seeds. Plant Dis. 79:193-195.

44. Pedersen, P., Gran, C., Cullen, E., and Hill, J. H. 2007. Potential for integrated management of soybean virus disease. Plant Dis. 91:1255-1259.

45. Peng, Y. H., Kadoury, D., Gal-On, A., Huet, H., Wang, Y., and Raccah, B. 1998. Mutations in HC-Pro gene of Zucchini yellow mosaic potyvirus: Effects on aphid transmission and binding to purified virions. J. Gen. Virol. 79:897-904.

46. Porto, M. D. M., and Hagedorn, D. J. 1975. Seed transmission of a Brazilian isolate of Soybean mosaic virus. Phytopathology 65:713-716.

47. Ren, Q., Pfeiffer, T. W., and Ghabrial, S. A. 1996. Soybean mosaic virus incidence level and infection time: interaction effects on soybean. Crop Sci. 37:1706-1711.

48. Roberts, I. M., Wang, D., Thomas, C. L., and Maule, A. J. 2003. Pea seedborne mosaic virus seed transmission exploits novel symplastic pathways to infect the pea embryo and is, in part, dependent upon chance. Protoplasma 222:31-43.

49. Rojas, M. R., Zerbini, F. M., Allison, R. F., Gilbertson, R. L., and Lucas, W. J. 1997. Capsid protein and helper component-proteinase function as potyvirus cell-to-cell movement proteins. Virology 237:283-95.

50. Roudet-Tavert, G., German-Retana, S., Delaunay, T., Delecolle, B.,
Candresse, T., and Le Gall, O. 2002. Interaction between potyvirus helper component-proteinase and capsid protein in infected plants. J. Gen. Virol. 83:1765-1770.

51. Rozen, S., and Skaletsky, H. J. 2000. Primer3 on the WWW for general users and for biologist programmers. Pages 365-386 in: Bioinformatics Methods and Protocols: Methods in Molecular Biology. S. Krawetz and S. Misener, eds. Humana Press, Totowa, NJ.

52. Saenz, P., Salvador, B., Simon-Mateo, C., Kasschau, K. D., Carrington, J. C., and Garcia, J. A. 2002. Host-specific involvement of the HC protein in the long-distance movement of potyviruses. J. Virol. 76:1922-1931.

53. Senda, M., Masuta, C., Ohnishi, S., Goto, K., Kasai, A., Sano, T., Hong, J., and MacFarlane, S. 2004. Patterning of virus-infected Glycine max seed coat is associated with suppression of endogenous silencing of chalcone synthase genes. Plant Cell 16:807-818.

54. Seo, J., Kang, S., Seo, B. Y., Jung, J. K., and Kim, K. 2010. Mutational analysis of interaction between coat protein and helper componentproteinase of Soybean mosaic virus involved in aphid transmission. Mol. Plant Pathol. 11:265-276.

55. Shukla, D. D., Strike, P. M., Tracy, S. L., Gough, K. H., and Ward, C. W. 1988. The N-termini and C-termini of the coat proteins of potyviruses are surface-located and the N-terminus contains the major virus-specific epitopes. J. Gen. Virol. 69:1497-1508.

56. Tatineni, S., Van Winkle, D. H., and French, R. 2011. The N-terminal region of Wheat streak mosaic virus coat protein is a host- and strainspecific long-distance transport factor. J. Virol. 85:1718-1731.

57. To, J. C. 1989. Effect of different strains of Soybean mosaic virus on growth, maturity, yield, seed mottling and seed transmission in several soybean cultivars. J. Phytopathol. 126:231-236.

58. Todd, J. J., and Vodkin, L. O. 1996. Duplications that suppress and deletions that restore expression from a chalcone synthase multigene family. Plant Cell 8:687-699.

59. Tuteja, J. H., Zabala, G., Varala, K., Hudson, M., and Vodkin, L. O. 2009. Endogenous, tissue-specific short interfering RNAs silence the chalcone synthase gene family in Glycine max seed coats. Plant Cell 21:3063-3077.

60. Wang, L., Eggenberger, A., Hill, J., and Bogdanove, A. J. 2006. Pseudomonas syringae effector avrB confers soybean cultivar-specific avirulence on Soybean mosaic virus adapted for transgene expression but effector avrPto does not. Mol. Plant-Microbe Interact. 19:304-312.

61. Yamagishi, N., Terauchi, H., Kanematsu, S., and Hidaka, S. 2006. Biolistic inoculation of soybean plants with soybean dwarf virus. J. Virol. Methods 137:164-167. 